\title{
Cortical Glutaminase, $\beta$-Glucuronidase and Glucose Utilization in Alzheimer's Disease
}

\author{
E.G. McGeer, P.L. McGeer, H. Akiyama and R. Harrop
}

\begin{abstract}
Large pyramidal neurons of rat and human neocortex stain immunohistochemically for phosphate-activated glutaminase (PAG). In a limited number of postmortem brains, we find large reductions in cortical PAG activity in Alzheimer's disease (AD). This finding is consistent with histological evidence that pyramidal neurons are affected in AD. The reductions are greater than those found in the same samples in choline acetyltransferase (ChAT) but the possible deleterious effects of coma and similar premortem factors on human PAG activity have yet to be assessed. The activity of $\beta$-glucuronidase, a lysosomal enzyme which occurs in reactive astrocytes, is elevated in the same samples. Positron emission tomography (PET) studies, using ${ }^{18} \mathrm{~F}$-fluorodeoxyglucose (FDG), have demonstrated significant deficiencies in glucose metabolism in the cortex in $\mathrm{AD}$, with the parietal, temporal and some frontal areas being particularly affected. We found in serial scans of $13 \mathrm{AD}$ cases, including one relatively young (44-46 year old) familial case, an exacerbation of the defect over time in most cases. We have found a negative correlation between the regional metabolic rates for glucose (LCMR(s)) measured premortem and the $\beta$-glucuronidase activities measured postmortem on a few AD cases that have come to autopsy. The correlations between LCMR(s) and PAG and ChAT activities tend to be positive. The results are consistent with previous suggestions that decreased LCMR(s) in AD reflect local neuronal loss and gliosis.
\end{abstract}

RÉSUMÉ: La glutaminase corticale, la-Glucuronidase et l'utilisation du glucose dans la maladie d'Alzheimer Les gros neurones pyramidaux du néocortex du rat et de l'humain captent la coloration immunohistochimique pour la glutaminase activée au prosphate (PAG). Dans un petit nombre de cerveaux prélevés à l'autopsie, nous observons des diminutions considérables dans l'activité corticale de la PAG dans la maladie d'Alzheimer (MA). Cette observation est compatible avec le fait que les neurones pyramidaux sont atteints dans la MA. Les diminutions sont plus grandes que celles que l'on retrouve dans les mêmes échantillons pour l'acétyltransférase de la choline (ChAT). Cependant, les effets néfastes possibles du coma et de phénomènes prémortem similaires sur l'activité de la PAG humaine n'ont pas encore été évalués. L'activité de la $\beta$-glucuronidase, un enzyme lysosomial qu'on retrouve dans astrocytose réactionnelle, est élevée dans ces échantillons. Les études effectuées par tomographie par émission de positrons (PET) utilisant le ${ }^{18}$ F-fluorodeoxyglucose (FDG), ont montré des déficiences significatives du métabolisme du glucose dans le cortex des patients atteints de MA, les zones pariétales, temporales et certaines zones frontales étant particulièrement atteintes. Nous avons observé lors de scans sériés chez 13 cas de MA, incluant un cas familial relativement jeune (4446 ans), une exacerbation du défaut au cours du suivi chez la plupart des cas. Nous avons établi qu'il existe une corrélation négative entre les taux métaboliques régionaux du glucose (LCMR(s)) mesurés prémortem et l'activité de la $\beta$ glucuronidase mesurée postmortem chez quelques cas de MA ayant subi une autopsie. La corrélation entre les LCMR(s) et l'activité de la PAG et de la ChAT avait tendance à être positive. Les résultats sont compatibles avec des suggestions faites précédemment selon lesquelles une diminution des LCMR(s) dans la MA reflète une perte neuronale locale et un processus de gliose.

Can. J. Neurol. Sci. 1989; 16:511-515

Morphological data on the distribution of plaques and tangles in Alzheimer's disease (AD) suggest that an important part of the pathology may be a degeneration of the pyramidal neurons forming corticocortical association projections. ${ }^{1-3}$ There is considerable evidence that these neurons may use glutamate as their excitatory transmitter. They stain heavily for glutamate 4,5 and retrogradely transport $\mathrm{D}-\left[{ }^{3} \mathrm{H}\right]$ aspartate; ${ }^{6}$ moreover, there is loss of high affinity $\left[{ }^{3} \mathrm{H}\right]$ glutamate uptake in the projecting nerve endings following axotomy. ${ }^{7}$ More recently, in rat and human cortex $^{8-10}$ and in rat and guinea pig hippocampus, 11 they have been shown to stain immunohistochemically for phosphate-activated glutaminase (PAG), a mitochondrial enzyme which catalyzes the hydrolysis of glutamine to glutamate and ammonia. PAG has been suggested as a possible mediator of the synthesis

From the Kinsmen Laboratory of Neurological Research, Dept. of Psychiatry, University of B.C., Vancouver (EGM, PLM and HA), and the School of Computer Science, Burnaby (RH), B.C.

Reprint requests to: Dr. Edith McGeer, Kinsmen Laboratory of Neurological Research, University of B.C., 2255 Westbrook Mall, Vancouver, B.C., Canada V6T IW5 
of neurotransmitter glutamate. Although PAG also appears in other locations, the marked loss of PAG-positive pyramidal neurons seen in initial immunohistochemical studies on postmortem AD brains ${ }^{10}$ suggested that a detailed biochemical study of the levels of this enzyme might be worthwhile. We report here preliminary postmortem data indicating marked decreases in cortical PAG activity in AD.

We also report preliminary data confirming and extending the findings of elevated cortical activity of $\beta$-glucuronidase in AD. Such elevated levels of this lysosomal enzyme were previously reported in AD temporal cortex and Huntington's disease putamen. ${ }^{12}$ This enzyme is found in reactive astrocytes, and its activity may therefore give some indication of the degree of astrocytosis. Since histological studies on the brains of AD cases who have received premortem positron emission tomography (PET) scans with $18 \mathrm{~F}$-fluorodeoxyglucose (FDG) suggest that the decreased metabolic rates seen in the cortex in AD may reflect neuronal loss and gliosis ${ }^{13}$ (and unpublished observations), we also mention the correlation between premortem PET scan data and postmortem enzyme activities in a few AD cases that have come to autopsy.

\section{Material and Methods}

The human brains used in this study were obtained postmortem within 3-24 hours of death through the autopsy services of the University Hospital, U.B.C. site. Small samples containing a full cortical thickness were dissected from multiple areas of the neocortex and frozen at $-70^{\circ} \mathrm{C}$ until assayed. All brains were subjected to extensive histopathological examination and the diagnosis of $\mathrm{AD}$ was based upon established histological criteria.

The samples were weighed and homogenized in 10 volumes of ice cold $0.25 \mathrm{M}$ sucrose or water (identical results were obtained with either medium) and kept on ice. A $40 \mu \mathrm{l}$ sample was mixed with $120 \mu \mathrm{l}$ of $67 \mathrm{mM}$ boric acid $/ 417 \mathrm{mM}$ potassium phosphate buffer ( $\mathrm{pH} 8.0$ ) and $40 \mu$ laliquots preincubated for 30 minutes at $25^{\circ} \mathrm{C}$. Ten $\mu$ l of an aqueous solution of ${ }^{14} \mathrm{C}(\mathrm{U})$-L-glutamine containing $120,000 \mathrm{dpm}$ (specific activity $67.5 \mathrm{mC} / \mathrm{mm}$ ) were added and the mixture incubated 15 minutes at $25^{\circ} \mathrm{C}$. The reaction was stopped by addition of $50 \mu \mathrm{l}$ of ice cold absolute ethanol and $950 \mu \mathrm{l}$ of $200 \mathrm{mM}$ sodium acetate (pH 4.5) containing 80 nmoles L-glutamic acid. The mixture was applied to an approximately $5 \times 20 \mathrm{~mm}$ Dowex 1-X8 (analytical grade, acetate form, $200-400$ mesh) column which was washed with $2 \times 5 \mathrm{ml}$ of water and eluted with $2 \mathrm{ml}$ of $1 \mathrm{~N} \mathrm{HCl}$. The radioactivity in the eluant was determined by liquid scintillation counting at an efficiency of approximately $87 \%$. This is a minor modification of the procedure of Kaneko et al ${ }^{14}$ and stud- ies in both rat and human tissue ${ }^{10}$ suggested it gave satisfactory results on frozen as well as fresh tissue samples.

A second $40 \mu \mathrm{l}$ aliquot of the initial homogenate was mixed with $110 \mu \mathrm{l}$ of a solution of $0.2 \%$ plasma albumin in $2.75 \%$ Triton-X100. After at least 10 minutes on ice, $30 \mu \mathrm{l}$ aliquots were mixed with $50 \mu \mathrm{l}$ of a freshly prepared solution of 1 volume of $0.1 \mathrm{M}$ choline chloride containing $0.25 \mathrm{mg} / \mathrm{ml}$ of eserine sulfate, 1 volume of $8 \mathrm{mM}$ EDTA, 2 volumes of $0.2 \mathrm{M}$ sodium phosphate buffer ( $\mathrm{pH} \mathrm{7.4),} \mathrm{which} \mathrm{is} 3.6 \%$ in $\mathrm{NaCl}$, and 1 volume of a $0.35 \mathrm{mM}$ solution of ${ }^{14} \mathrm{C}$-acetylcoenzyme $\mathrm{A}$ (specific activity $0.67 \mathrm{mC} / \mathrm{mm}$ ) and the mixture incubated for 20 minutes at $37^{\circ} \mathrm{C}$. The reaction was stopped by addition of $1 \mathrm{ml}$ of an 0.15 $\mathrm{mM}$ solution of acetylcholine bromide or acetylcholine chloride in $0.1 \mathrm{~N}$ acetic acid/ $0.025 \mathrm{~N}$ perchloric acid. After addition of

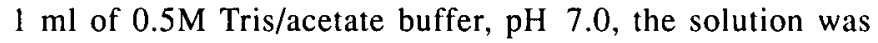
applied to an approximately $5 \times 20 \mathrm{~mm}$ column of amberlite CG-50, preswelled in water, which had been treated with $2 \mathrm{ml}$ of the same Tris/acetate buffer. The column was washed twice with $5 \mathrm{ml}$ and then with about $25 \mathrm{ml}$ of water and eluted with $3 \mathrm{ml}$ of $4 \mathrm{~N}$ acetic acid. Radioactivity in the eluant was determined by liquid scintillation counting. 15

Glucuronidase activity was determined by a modification of the fluorometric method of Cross et al. ${ }^{12}$ Briefly, each $50 \mu \mathrm{l}$ aliquot of an initial homogenate was incubated for 1 hour at $37^{\circ} \mathrm{C}$ with $950 \mu \mathrm{l}$ of an $0.3 \mathrm{mM}$ solution of 4 -methylumbelliferyl-d-glucuronide in $105 \mathrm{mM}$ sodium acetate, $\mathrm{pH} 4.0$. The reaction was stopped by addition of $2 \mathrm{ml}$ of $1 \mathrm{M}$ glycine solution made to $\mathrm{pH} 10.4$ with sodium hydroxide. The mixtures were lightly centrifuged and the fluorescence read on the supernatants at an activation wave length of 365 and a fluorescent wave length of 460 . Standard solutions containing $0-8 \mathrm{~nm}$ of 4-methylumbelliferone, made up in a suitable mixture of $100 \mathrm{mM}$ sodium acetate and the $1 \mathrm{M}$ glycine/ $\mathrm{NaOH}$ solution, gave highly linear and reproducible results and the fluorescence in both standards and reaction supernatants was stable for at least 24 hours if the solutions were stored in the dark at room temperature. Preliminary studies confirmed 12 the applicability of the assay to frozen tissue and its linearity over the time and tissue concentrations used.

Rat tissue was run with each group of human samples and gave highly reproducible results from day to day in all the assays used.

Protein was determined by the method of Lowry et al ${ }^{16}$ on $40 \mu \mathrm{l}$ aliquots of the same homogenate-phosphate buffer mixture used for glutaminase determinations.

The procedures used for obtaining and analyzing the PET scans have been detailed elsewhere. ${ }^{17}$

Radioactive materials were obtained from New England Nuclear and the other chemicals were from Sigma or Fisher Scientific.

Figure 1 -Regional enzyme activities in AD cases as percent of control mean for each region. Regions are arranged in ascending order of preservation of ChAT activity and are (Brodmann \#) (No. of AD cases/no. of controls]: I) supramarginal gyrus, (\#40) [1213];2) inferior temporal gyrus, (\#37) [12/3]; 3) lateral occipital-temporal gyrus (36) [8/2]; 4) superior parietal area (7b) [4/2]; 5) superior temporal gyrus (22) [11/3]; 6) angular gyrus (39) [9/4]; 7) occipital gyrus (19) [9/3]; 8) hippocampus [10/2]; 9) entorhinal area (28) [8,3]; 10) angular gyrus, inferior (39) [13/3]; 11) middle temporal (21) (15/8); 12) inferior temporal (20) [12/3]; 13) parahippocampal gyrus (27/35) [9/3]; 14) premotor area (6) (10/3]; 15) middle frontal gyrus (46) (14/3]; 16) occipital pole (17) [16/8]; 7) Broca area (44) (15/7]; 18) temporal tip (38) (17/7]; 19) superior frontal gyrus (9) [13/3]; 20) cingulate anterogenual (33/24) [11/3]; 21) frontal pole (10) [15/8]; 22) postcentral gyrus (1/2/3) (16/8]; 23) cingulate retrosplenial $(26 / 29 / 30) 3 / 2] ; 24)$ precentral gyrus (4) [16/8]; 25) putamen [8/2]; 26) caudate [8/2].

A. ChAT Activity. B. PAG Activity C. $\beta$-Glucuronidase Activity. The control means $(+S E)$ are not shown in $1 A$ and $1 B$ because they obscured the spread of the $A D$ data. Note differences in the $Y$ axis in the three figures. 

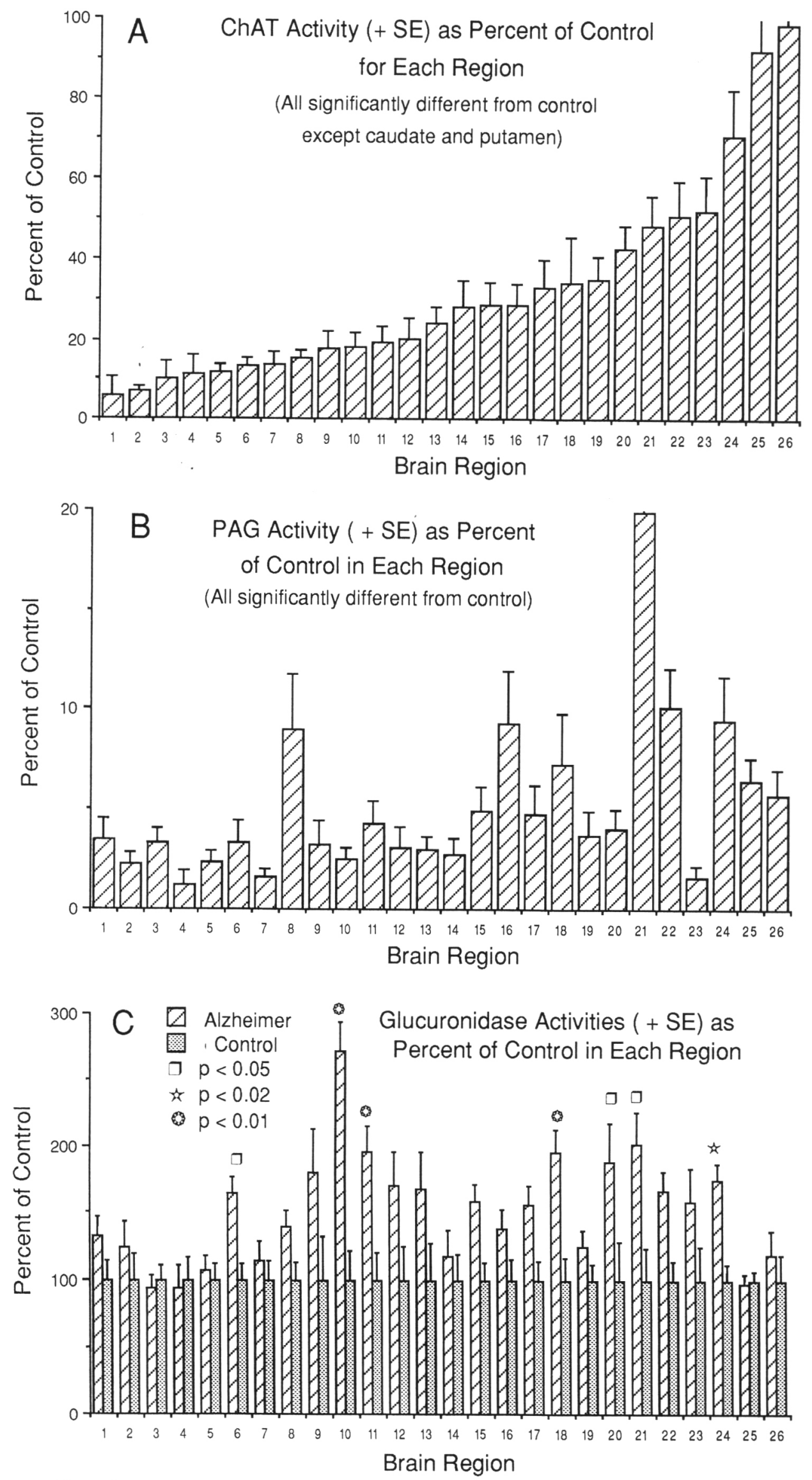

Figure 1 


\section{RESULTS}

\section{Enzyme Assays}

Mean (+S.E.M.) activities of ChAT, PAG and $\beta$-glucuronidase found in samples of 26 brain regions in a group of AD cases are indicated in Figure 1; for simplicity the data are shown as percent of the control mean found for the enzyme in each particular region. Too few control data were available to allow analysis for the effect of factors such as age, postmortem delay and coma, but the means of the first two were almost identical (certainly not significantly different) between the $A D$ and control groups.

Conclusions from these results must be considered as temporary because of the small number of control data for many of the regions. With that caveat, however, it appears that percent decreases in PAG are greater than those found in ChAT in the same brain homogenates and there is very little correlation between the regional losses in the two enzymes. Despite the smallness of the number of controls for many regions, ANOVA analyses, followed by student $t$ tests, indicated significant differences between control and AD means for PAG in all 26 regions and for ChAT in all except the caudate and putamen.

$\beta$-Glucuronidase activities tended to be higher in the AD than control cases in most regions but the difference only reached statistical significance in seven areas (Figure 1C). There again appeared to be relatively little correlation between regional effects on $\beta$-glucuronidase and those on ChAT or PAG.

\section{PET Results and Enzyme Activities}

In our hands 17,18 (and manuscript submitted), as in others, 19 PET studies using FDG have demonstrated significant deficiencies in glucose metabolism in the cortex in $\mathrm{AD}$, with the parietal, temporal and some frontal areas being particularly affected. Serial scans on AD cases generally show an exacerbation over time which varies from case to case (e.g. Figure 2) and region to region of cortex. It was interesting that the case of young, familial AD showed no greater rate of decline in regional metabolic rate for glucose (LCMR) in any region, or on the average over

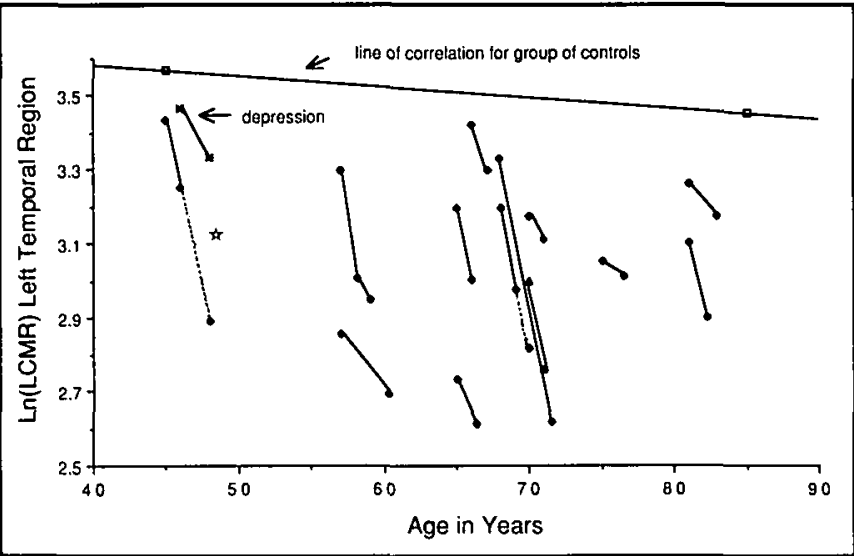

Figure $2-\operatorname{Ln}(L C M R)$ in the left middle temporal gyrus as a function of age in a group of 20 controls (highly significant regression line), and in $13 A D$ cases and one patient with depression who received repeat scans. The lines for two $A D$ cases are extrapolated to show the dates of death; the $\operatorname{Ln}(L C M R)$ s were not known on those dates; Figure 3 refers to the case starred in this figure. all the cortical regions examined, than many of the older cases studied (manuscript submitted). A number of PET scanned AD cases have now come to autopsy and we have been interested in examining the possible relationship of $\operatorname{LCMR}(\mathrm{s})$ determined from the premortem PET scans to the regional enzyme activities examined postmortem. In pilot studies done so far, there generally seems to be within each brain a negative correlation between the LCMR(s) and $\beta$-glucuronidase activities (Figure 3A). The correlations of LCMR(s) with ChAT (Figure 3B) or PAG activities (not exemplified) are in the positive direction but are often of low significance.

\section{Discussion}

The ChAT data are consistent with results from many laboratories showing a fall in cortical levels in AD with general preservation of striatal ChAT activities. The data showing increased $\beta$-glucoronidase activities in many areas of the cortex in $\mathrm{AD}$ are consistent with the previous report of Cross et al ${ }^{12}$ and may reflect the increase in astrocytes and, possibly, microglia ${ }^{20}$ and leucocytes ${ }^{21}$ found in AD cortex. Those areas showing the most significant differences in $\beta$-glucuronidase between the $\mathrm{AD}$ and control groups in this limited series are all in the temporal lobe, a finding which is consistent with the known heavy involvement of this lobe in AD pathology. The

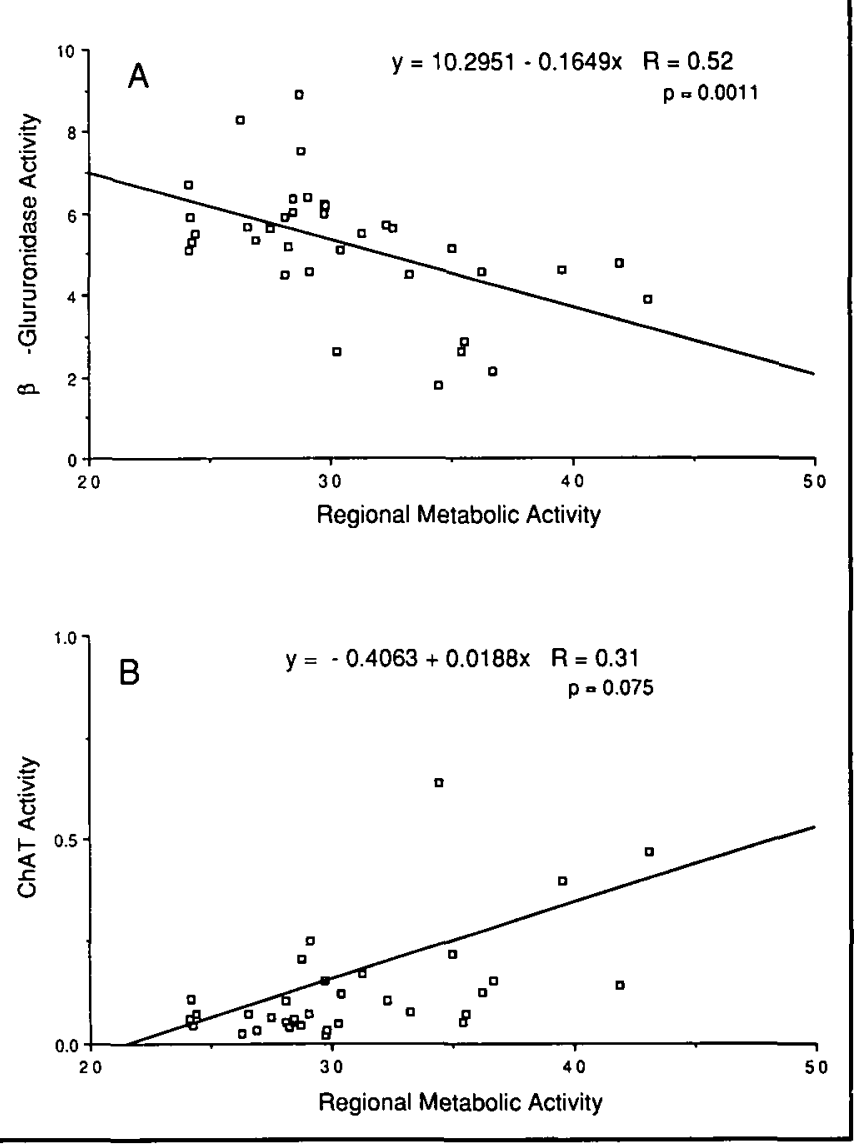

Figure 3 -Plots of $\beta$-glucuronidase $(A)$ and ChAT $(B)$ activities determined postmortem in various regions of the brain of a young, familial AD case (starred in Figure 2) against the LCMR(s) determined from the last premortem PET scan. 
apparent negative correlation we have found in a number of PET scanned cases between the cortical LCMR(s) determined premortem and the $\beta$-glucuronidase activities determined postmortem (e.g. Figure $3 \mathrm{~A}$ ) is consistent with previous suggestions $^{13}$ that the decreases in metabolism reflect local neuronal loss and gliosis.

The data on PAG are difficult to interpret and the relevant literature is controversial. 22 Large decreases in cortical PAG in $A D$ are not unexpected in view of the studies, reviewed in the introduction, which indicate that the pyramidal neurons of the cortex stain intensely for PAG-like immunoreactivity and that these neurons are heavily involved in AD pathology. Other neurons, such as the GABAergic ones, are, however, positive in the cortex ${ }^{10}$ and it is unlikely that these are affected to any great extent in AD. Cortical glutamate concentrations have been reported decreased in both postmortem and biopsied temporal cortex in $A D$ and $D-\left[{ }^{3} \mathrm{H}\right]$ aspartate binding has been found decreased in postmortem tissue, suggesting possible losses in glutamate neuronal structures, but it is difficult to reconcile the present data with the reported lack of decrease in PAG activity in AD biopsied specimens. ${ }^{23}$ It seems highly possible that PAG activity, like glutamate decarboxylase, 24 may be markedly affected by premortem coma, postmortem delay, and similar epiphenomena. Studies are continuing in an attempt to define the importance of such factors.

\section{ACKNOWLEDGEMENTS}

This work was supported by grants from the Medical Research Council of Canada and the Alzheimer Society of B.C., as well as donations from individual British Columbians. We thank Anne Bui, Edith Singh and members of the U.B.C. PET-TRIUMF team for their help.

\section{REFERENCES}

1. Lewis DA, Campbell MJ, Terry RD, et al. Laminar and regional distribution of neurofibrillary tangles and neuritic plaques in Alzheimer's disease: a quantitative study of visual and auditory cortices. J Neurosci 1987; 7: 1799-1808.

2. Pearson RCA, Esiri MM, Hioms RW, et al. Anatomical correlates of the distribution of pathological changes in the neocortex in Alzheimer's disease. Proc Natl Acad Sci USA 1985; 82: 45314534.

3. Rogers J, Morrison JH. Quantitative morphology and regional laminar distributions of senile plaques in Alzheimer's disease. J Neurosci 1985; 5: 2801-2808.

4. Conti F, Rustioni A, Petrusz P, et al. Glutamate-positive neurons in the somatic sensory cortex of rats and monkeys. J Neurosci 1987; 7: 1887-1901.

5. Storm-Mathisen J, Leknes AK, Bose AT, et al. First visualization of glutamate and GABA in neurones by immunocytochemistry. Nature 1983; 301: 517-520.

6. Rustioni A, Cuenod M. Selective retrograde transport of D-aspartate in spinal interneurons and cortical neurons of rats. Brain Res 1982; 236: 143-155.
7. McGeer PL, Eccles JC, McGeer EG. Molecular Neurobiology of the Mammalian Brain. New York; Raven Press, 1987: 180-186.

8. Donaghue JP, Wenthold RJ, Altschuler RA. Localization of glutaminase-like and aspartate aminotransferase-like immunoreactivities in neurons of cerebral cortex. J Neurosci 1985; 5: 2597 . 2608.

9. Kaneko T, Mizuno N. Immunohistochemical study of glutaminasecontaining neurons in the cerebral cortex and thalamus of the rat. J Comp Neurol 1988; 267: 599-602.

10. Akiyama H, McGeer PL, Itagaki S, et al. Loss of glutaminase-positive cortical neurons in Alzheimer's disease. Neurochem Res 1989; 14: 453-458.

11. Altshuler RA, Monaghan DT, Haser WG, et al. Immunocytochemical localization of glutaminase-like and aspartate aminotransferase-like immunoreactivities in the rat and guinea pig hippocampus. Brain Res 1985; 330: 225-233.

12. Cross AJ, Crow TJ, Dawson JM, et al. Subcellular pathology of human neurodegenerative disorders: Alzheimer-type dementia and Huntington's disease. J Neurochem 1986; 47: 882-889.

13. McGeer PL, Kamo H, Harrop R, et al. Comparison of PET, MRI and CT with pathology in a proven case of Alzheimer's disease. Neurology 1986; 36: 1569-1574.

14. Kaneko T, Urade Y, Watanabe $Y$, et al. Production, characterization and immunohistochemical application of monoclonal antibodies to glutaminase purified from rat brain. J Neurosci 1987; 7: 302 309.

15. McGeer EG, Singh EA, McGeer PL. YGlutamyl transferase: normal cortical levels in Alzheimer's disease. Alz Dis Assoc Disord 1987; 1: 50-63.

16. Lowry $\mathrm{OH}$, Rosebrough NJ, Farr AL, et al. Protein measurement with the Folin phenol reagent. J Biol Chem 1951; 193: 265-275.

17. McGeer PL, Kamo H, Harrop R, et al. Positron emission tomography in patients with clinically diagnosed Alzheimer's disease. Can Med Assoc J 1986; 134: 597-607.

18. Akiyama H, Harrop R, McGeer PL, et al. Crossed cerebellar and uncrossed basal ganglia and thalamic diaschisis in Alzheimer's disease. Neurology 1989; 39: 541-548.

19. McGeer PL. Brain imaging in Alzheimer's disease. Br Med Bull 1986; 42: 24-28.

20. McGeer PL, Itagaki S, Tago $\mathrm{H}$, et al. Reactive microglia in patients with senile dementia of the Alzheimer type are positive for the histocompatibility protein HLA-DR. Neurosci Lett 1087; 79: 195-200.

21. Itagaki S, McGeer PL, Akiyama H. Presence of T-cytotoxic suppressor and leucocyte common antigen positive cells in Alzheimer's disease brain tissue. Neurosci Lett 1988; 91: 259. 264.

22. Procter AW, Lowe SL, Palmer AM, et al. Topographical distribution of neurochemical changes in Alzheimer's disease. J Neurol Sci 1988; 84: 125-140.

23. Francis PT, Bowen DM. Tacrine, a drug with therapeutic potential for dementia: post-mortem biochemical evidence. Can J Neurol Sci (in press - this symposium).

24. McGeer PL, McGeer EG. Enzymes associated with the metabolism of catecholamines, acetylcholine and GABA in human controls and patients with Parkinson's disease and Huntington's chorea. J Neurochem 1976; 26: 65-76 